\title{
Combination of high throughput and structural screening to assess protein stability - A screening perspective
}

Pohl, Christin; Mahapatra, Sujata; Kulakova, Alina; Streicher, Werner; Peters, Günther H.J.; Nørgaard, Allan; Harris, Pernille

\section{Published in:}

European Journal of Pharmaceutics and Biopharmaceutics

Link to article, DOI:

10.1016/j.ejpb.2021.08.018

Publication date:

2022

Document Version

Publisher's PDF, also known as Version of record

Link back to DTU Orbit

Citation (APA):

Pohl, C., Mahapatra, S., Kulakova, A., Streicher, W., Peters, G. H. J., Nørgaard, A., \& Harris, P. (2022).

Combination of high throughput and structural screening to assess protein stability - A screening perspective.

European Journal of Pharmaceutics and Biopharmaceutics, 171. https://doi.org/10.1016/j.ejpb.2021.08.018

\section{General rights}

Copyright and moral rights for the publications made accessible in the public portal are retained by the authors and/or other copyright owners and it is a condition of accessing publications that users recognise and abide by the legal requirements associated with these rights.

- Users may download and print one copy of any publication from the public portal for the purpose of private study or research.

- You may not further distribute the material or use it for any profit-making activity or commercial gain

- You may freely distribute the URL identifying the publication in the public portal 


\title{
Combination of high throughput and structural screening to assess protein stability - A screening perspective
}

\author{
Christin Pohl ${ }^{\mathrm{a}, \mathrm{b}, 1, *}$, Sujata Mahapatra ${ }^{\mathrm{a}, \mathrm{b}, 2}$, Alina Kulakova ${ }^{\mathrm{c}}$, Werner Streicher ${ }^{\mathrm{a}, 3}$, Günther H. \\ J. Peters ${ }^{\mathrm{b}}$, Allan Nørgaard ${ }^{\mathrm{a}}$, Pernille Harris ${ }^{\mathrm{b}, 4, "}$

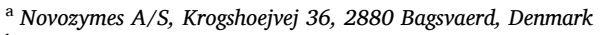 \\ ${ }^{\mathrm{b}}$ Technical University of Denmark, Department of Chemistry, Kemitorvet 207, 2800 Kongens Lyngby, Denmark \\ ${ }^{\mathrm{c}}$ Department of Chemistry, University of Copenhagen, Universitetsparken 5, 2100 Copenhagen, Denmark
}

\section{A R T I C L E I N F O}

\section{Keywords:}

High throughput screening

Drug screening

Small-angle X-ray scattering (SAXS)

Protein stability

Protein-protein interaction

Protein aggregation

Protein engineering

\begin{abstract}
A B S T R A C T
High throughput screening for measuring the stability of industrially relevant proteins and their variants is necessary for quality assessment in the development process. Advances in automation, measurement time and sample consumption for many techniques allow rapid measurements with minimal amount of protein. However, many methods include automated data analysis, potentially neglecting important aspects of the protein's behavior in certain conditions. In this study we implement small angle X-ray scattering (SAXS), typically not used to assess protein behavior in industrial screening, in a high throughput screening workflow to address problems of contradicting results and reproducibility among different high throughput methods. As a case study we use the lipases of Thermomyces lanuginosus and Rhizomucor miehei, widely used industrial biocatalysts. We show that even the initial analysis of the SAXS data without performing any time-consuming modelling provide valuable information on interparticle interactions. We conclude that recent advances in automation and data processing, have enabled SAXS to be used more widely as a tool to gain in-depth knowledge highly useful for protein formulation development. This is especially relevant in light of increasing accessibility to SAXS due to the commercial availability of benchtop instruments.
\end{abstract}

\section{Introduction}

In most cases, the development of industrially relevant proteins involves many different variants of a naturally occurring protein, produced by protein engineering. The evaluation of the stability of these variants requires screening in a high throughput fashion. Many commonly used systems for high throughput screening involve microtiter plates, which are commercially available in up to 9600 -well formats. Due to practical handling, the 96 or 384-well format is often used. Production of industrially relevant proteins, such as enzymes, typically follows an established workflow of different phases [1,2]; high throughput generation of mutants, followed by activity screening. For enzymes or proteins that show desired properties, more in-depth characterization is carried out. This involves determining stability, which is typically done by a range of high throughput and automated biophysical methods. While these techniques are rapid and consume low amounts of sample, information about protein-protein interaction and structural knowledge is severely limited. Small angle X-ray scattering is not commonly used as a high throughput or screening method, but is a powerful tool for structural determination of proteins in solution at low

\footnotetext{
Abbreviations: C, degree Celsius; DLS, dynamic light scattering; $\mathrm{GnHCl}$, Guanidine hydrochloride; ICD, isothermal chemical denaturation; $k_{D}$, Diffusion interaction

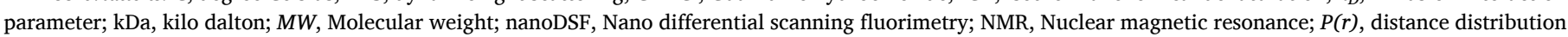

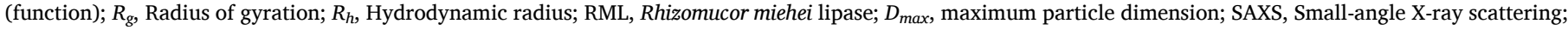
TLL, Thermomyces lanuginosus lipase.

* Corresponding authors at: Novozymes A/S, Krogshoejvej 36, 2880 Bagsvaerd, Denmark (C. Pohl).

E-mail addresses: christin.pohl@biochemistry.lu.se (C. Pohl), phharris@chem.ku.dk (P. Harris).

1 Present address: Lund University, Department of Biochemistry and Structural Biology, Box 124, 22100 Lund, Sweden.

2 Present address: Aarhus University, Department of Molecular Biology and Genetics, Gustav Wieds Vej 10, 8000 Aarhus, Denmark.

3 Present address: NanoTemper Technologies GmbH, Floessergasse 4, 81369 Muenchen, Germany.

${ }^{4}$ Present address: Department of Chemistry, University of Copenhagen, Universitetsparken 5, 2100 Copenhagen, Denmark.
} 
resolution and the analysis of flexible and multi domain systems [3]. Recent advances in automation and sample consumption have propelled efforts to include SAXS in high throughput screening [4,5]. In our study we combine common high throughput screening methods with SAXS measurements to maximize our understanding of the lipases of Thermomyces lanuginosus (TLL) and Rhizomucor miehei (RML). These lipases are used as a case study due to their high relevance in different industries.

Lipases are widely used as biological catalysts in industry, due to their high specificity and wide recognition of different substrates; for example in the pharmaceutical industry [6-8] or in the food industry [9-11]. TLL and RML are important catalysts in the food industry, biodiesel production and enantioselective or synthetic processes [12-16]. Both lipases have an $\alpha / \beta$ fold $[17,18]$ with an active site consisting of a Ser-His-Asp catalytic triad covered by a mobile helical loop referred to as lid, a common feature for lipases. TLL and RML are similar in size (TLL: 31.7 kDa. RML: $29.5 \mathrm{kDa}$ ) and isoelectric point (TLL: 4.4: RML: 4.7). The amino acid sequence identity between TLL and RML is $34.4 \%$ with a similarity of $48.2 \%$ [19]. Structurally, TLL and RML are similar (all atom RMSD: $1.157 \AA$ ) [20] (Fig. S1).

TLL maintains its activity up to $60^{\circ} \mathrm{C}$ [21] with maximum activity around $\mathrm{pH} 9$ [22]. However, TLL is known to form aggregates, which compromise the enzymatic activity [23]. Betaine has been shown to have a positive effect on TLL's stability towards thermal and chemical induced unfolding [24], but aside from that no systematic study of TLL stability in different buffer or excipient conditions has been reported. RML shows lower thermostability that limits its broader applications at higher temperatures $[25,26]$. The effects of polyhydric alcohols and salts on the thermal stability of RML were studied [26], indicating that polyhydric alcohols are more effective than salts against thermal inactivation. In addition, the study showed that the effect of salts depends on their nature and concentration. The ability to improve stability and change aggregation propensities of both lipases by changing $\mathrm{pH}$ and/or addition of salt and excipients was therefore the starting point of our study.

The aim was to improve stability screening of aggregation prone proteins by implementing SAXS into a high throughput screening approach. In the context of the EU international training network project on 'protein excipient and protein-protein interaction in formulation (PIPPI)', TLL and RML were selected as representative proteins with an $\alpha / \beta$ fold of industrial relevance [27]. Our screening strategy was based on a stepwise assessment of the conformational stability and initial dispersion state. Initially, we performed a systematic high throughput $\mathrm{pH}$ and salt screen. Two $\mathrm{pH}$ conditions were chosen and the stability was assessed in presence of excipients and in different buffer systems. We used differential scanning fluorimetry (DSF) to measure stability towards temperature-induced unfolding and isothermal chemical denaturation (ICD) to determine stability towards chemical denaturants. The initial dispersion state and the colloidal stability was evaluated using dynamic light scattering (DLS). We implemented SAXS measured in selected conditions into this screening approach to assess interparticle interactions, aggregation propensity and protein flexibility. Additionally, we applied size exclusion chromatography in combination with multi-angle light scattering (SEC-MALS) to verify our results obtained from SAXS.

Additionally, we assessed the sample consumption, automation, and content of information of the applied methods. We believe that this screening approach is applicable to a wide range of industrially relevant proteins, including for example protein pharmaceutics.

\section{Material and methods}

\subsection{Screening approach}

A systematic high throughput $\mathrm{pH}$ and salt screen from $\mathrm{pH} 5$ to 9 with 0,70 and $140 \mathrm{mM}$ sodium chloride was performed (Fig. S2, screen I).
Two $\mathrm{pH}$ conditions (pH 5.5 and $\mathrm{pH}$ 7.5) were chosen. The stability was assessed in presence of excipients $(280 \mathrm{mM}$ sucrose, $140 \mathrm{mM}$ arginine $\bullet \mathrm{HCl}$ and $280 \mathrm{mM}$ proline, Fig. S2, screen II). Additionally, the protein stability was assessed in different buffer systems (acetate and phosphate buffer). Based on the results of the high throughput screening, SAXS was measured in histidine buffer $\mathrm{pH} 5.5$ and $\mathrm{pH}$ 7.5, acetate buffer $\mathrm{pH} 5.5$ and phosphate buffer pH 7.5. For TLL, SAXS was additionally measured in presence of salt and excipients (arginine•HCl).

\subsection{Sample preparation}

All samples were dialyzed as described in Pohl et al. [28] using SlideA-Lyzer ${ }^{\mathrm{TM}}$ 10,000 MWCO dialysis cassettes (Thermo Fisher, US). The protein concentration after dialysis was measured using a NanoDrop ${ }^{\mathrm{TM}}$ 8000 Spectrophotometer (Thermo Fisher, US). If not stated otherwise, all measurements were performed at a protein concentration of $1 \mathrm{mg} /$ $\mathrm{ml}$, obtained by dilution into the final condition. Filtration of the sample and buffer was performed using Luer-Lok ${ }^{\mathrm{TM}}$ syringes (BD, Canada) and $0.22 \mu \mathrm{m}$ Millex®-GV filter (Merck, Germany).

Screen I: Samples where dialyzed at pH 5.5 and 7 (10 mM histidine buffer) and pH 8.5 (10 mM Tris). A protein stock solution of $20 \mathrm{mg} / \mathrm{ml}$ was made by dilution with the dialysis buffer. Stock solutions for the final conditions were prepared and the $\mathrm{pH}$ was adjusted if necessary. The sample was diluted 20 times into the final conditions.

Screen II: Samples were dialyzed at pH 5.5 (10 mM histidine and 10 $\mathrm{mM}$ sodium acetate buffer) and at pH 7.5 (10 mM histidine and $10 \mathrm{mM}$ phosphate buffer). A protein stock of $2 \mathrm{mg} / \mathrm{ml}$ was made by dilution with the dialysis buffer. Stock solutions for the final conditions were prepared and the $\mathrm{pH}$ was adjusted if necessary. The sample was diluted 2 times into the final conditions. For setup of this study and tested conditions, see Fig. S2.

\subsection{DLS measurements}

All samples were dialyzed as described above, filtered to avoid the presence of dust and the concentration was measured. All samples were centrifuged $10 \mathrm{~min}$ at $14,000 \mathrm{rcf}$ to exclude any remaining dust and large aggregates. The top $2 / 3$ were used for the measurement. Measurements were performed with a DynaPro® Plate Reader ${ }^{\mathrm{TM}}$ II (Wyatt Technology, US) using Aurora 384 LV/EB plates (Brooks Life Science, US). Silicone oil (Sigma Aldrich, Germany) was used for sealing the wells. Measurements were performed at isothermally at $25^{\circ} \mathrm{C}$ with $5 \mathrm{~s}$ acquisition time and 20 acquisitions per well. Aggregation onset $T_{\text {agg }}$ measurements were performed using a linear temperature gradient from $25^{\circ} \mathrm{C}$ to $80^{\circ} \mathrm{C}$ with $0.1{ }^{\circ} \mathrm{C} / \mathrm{min}$. 3 acquisitions with $3 \mathrm{~s}$ acquisition time were used to determine $T_{\text {agg. }}$. The interaction parameter $k_{D}$ was determined using a concentration series of 8 different protein concentrations between 1 and $10 \mathrm{mg} / \mathrm{ml} .20$ acquisitions with $5 \mathrm{~s}$ acquisition time were used to determine $k_{D}$. All formulations were measured in technical triplicates. Analysis was performed in DYNAMICS version 7.8.1.3.

\section{4. nanoDSF measurements}

Samples were prepared as described above, filtered and the concentration was measured. The measurements were performed using Prometheus NT.48 (NanoTemper Technologies, Germany). A constant temperature ramp was applied from 20 to $95{ }^{\circ} \mathrm{C}$ with $1{ }^{\circ} \mathrm{C} / \mathrm{min}$. The unfolding curve was visualized by plotting the fluorescence intensity at 330 and $350 \mathrm{~nm}$ as a ratio $\mathrm{F}_{350} / \mathrm{F}_{330}$ and the inflection point and the onset of unfolding were determined. Analysis was performed with PR. ThermControl (NanoTemper Technologies, Germany).

\subsection{ICD measurements}

Sample preparation was performed as described above, filtered and the concentration was measured. A protein stock solution of $1 \mathrm{mg} / \mathrm{ml}$ 
was prepared. Formulation and denaturation buffers for the desired conditions were prepared; denaturation buffer included $6 \mathrm{M} \mathrm{GnHCl}$ in the formulation buffer. Measurements were performed using Unchained Labs HUNK system - AVIA ICD 2304 (Unchained Labs). The incubation time was determined to $5 \mathrm{~h}$ and a gain of 100 was used for fluorescence detection, determined by an incubation and gain test performed prior to the unfolding measurements. For the determination of the unfolding curve a linear gradient of 48 points with increasing denaturant concentrated was generated. The protein was diluted 12.5 times dilution into all 48 denaturation conditions (final protein concentration: $80 \mu \mathrm{g}$ / $\mathrm{ml})$. For excitation a wavelength of $285 \mathrm{~nm}$ was used and the emission spectrum from 300 to $450 \mathrm{~nm}$ was measured. Analysis was performed with Formulator (Unchained Labs). The fluorescence maxima of the folded protein $(0 \mathrm{mM} \mathrm{GnHCl})$ and of the unfolded protein $(5.4 \mathrm{M} \mathrm{GnHCl})$ was taken and the unfolding curve was determined using the fluorescence ratio of $\mathrm{F}_{356} / \mathrm{F}_{344} \mathrm{~nm}$ for TLL and $\mathrm{F}_{354} / \mathrm{F}_{346}$ for RML.

\subsection{SEC-MALS}

SEC-MALS was performed on the Agilent 1260 Infinity II LC System (Agilent, US) with Agilent 1230 infinity (Agilent, US), Dawn Heleos-II (Wyatt Technology, US), and Optilab rex $633 \mathrm{~nm}$ (Wyatt Technology, US) detectors. Samples were prepared by diluting protein stock solutions with dialysis buffer and $50 \mu$ l were injected onto a Superdex 200 10/300 column (GE Healthcare, US). Measurements were performed at room temperature with a flowrate of $0.45 \mathrm{ml} / \mathrm{min}$. Data collection and processing were performed using the ASTRA software V7.2 (Wyatt Technology, US).

\subsection{SAXS measurements}

Sample preparation was performed as described above. All samples and dialysis buffers were filtered. The concentration of all samples was determined using NanoDrop ${ }^{\mathrm{TM}} 1000$ (Thermo Fisher Scientific, US). A concentration series was obtained by dilution with the dialysis buffer. Measurements were performed at the German Electron Synchrotron DESY at the P12 EMBL BioSAXS beamline. The data analysis was performed using the ATSAS software package version 2.8.4 [29]. The apparent molecular weight $M W$, radius of gyration $R_{g}$ and maximum particle dimension $D_{\max }$ were determined using PRIMUS [30]. A summary of the SAXS data collection is shown in Table S1.

For all measurements final graphs were made with MATLAB (MathWorks, US), Origin ${ }^{\circledR} 2019$ (OriginLabs, US) and GraphPad Prism version 9.1.1 (GraphPad Software, US)

\section{Results}

\subsection{High throughput screening of TLL}

When measured over the whole $\mathrm{pH}$ range, nanoDSF and ICD showed that the conformational stability of TLL was highest at pH 6 (Fig. S3). However, the effect of $\mathrm{NaCl}$, excipients and different buffer systems were less clear (Fig. 1A,B and Fig. S4). The analysis of chemically induced unfolding was complicated by two unfolding transitions (Fig. S5). The addition of excipients induced a third transition into the chemically induced unfolding of TLL in most conditions. The obtained $\Delta G$ values (Fig. S6) from the three-state model were therefore uncertain and only the inflection point of the chemically induced unfolding was used to evaluate the effect of excipients and different buffers on the chemical induced unfolding of TLL. Interestingly, the presence of arginine $\bullet \mathrm{HCl}$ and $\mathrm{NaCl}$ had an influence on the shape of the thermal induced unfolding curve (Fig. 1C). This effect was more pronounced at $\mathrm{pH} 7.5$ than at pH 5.5 (Fig. S7).

The initial dispersion in the sample, temperature induced

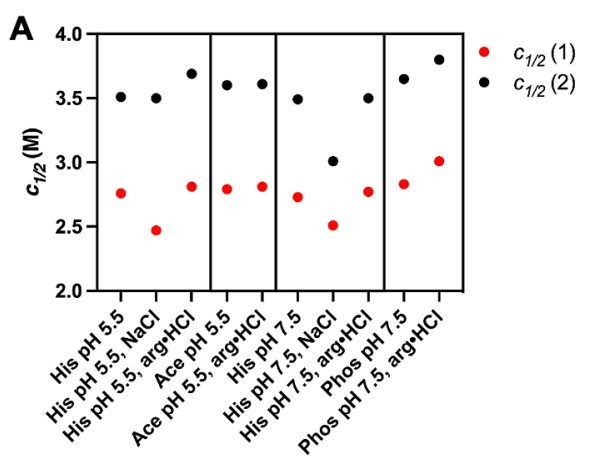

D

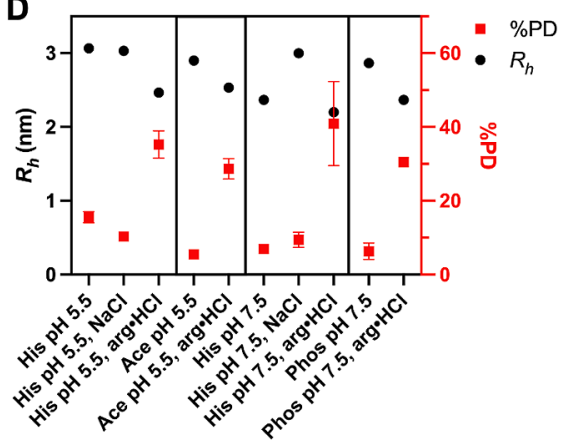

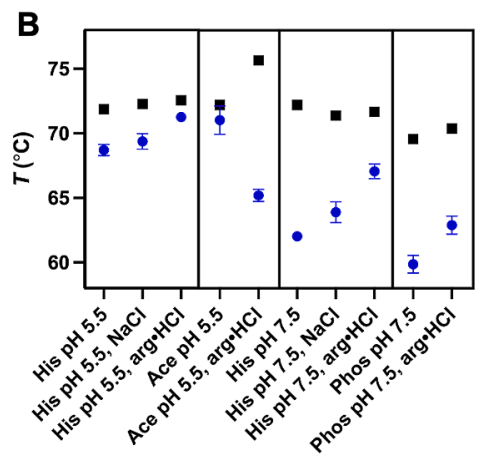

E

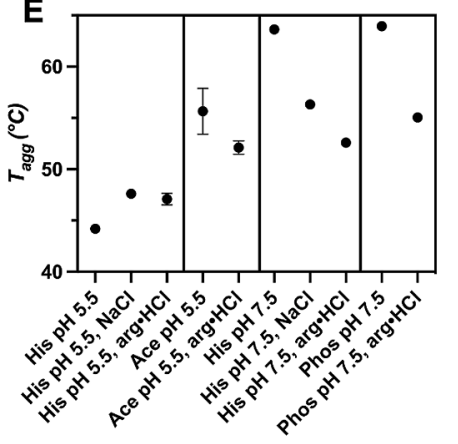

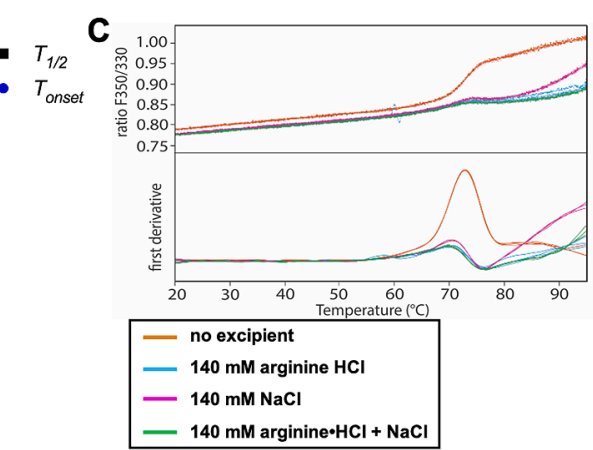

F

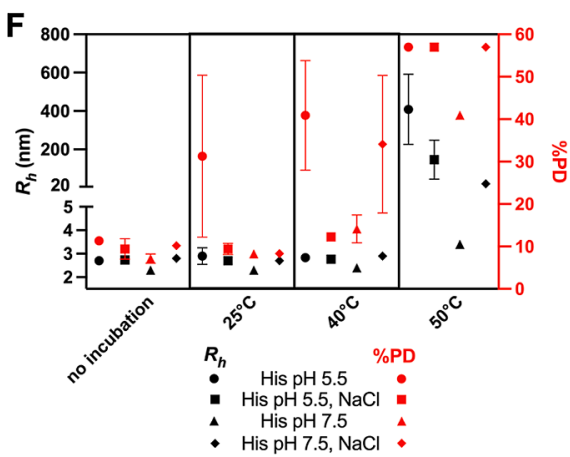

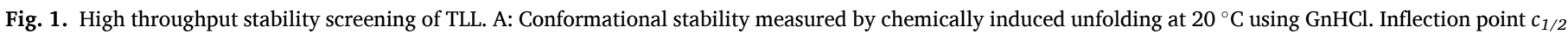

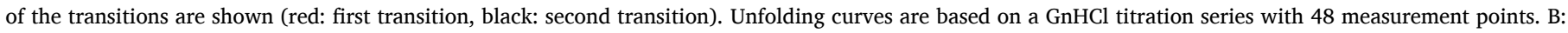

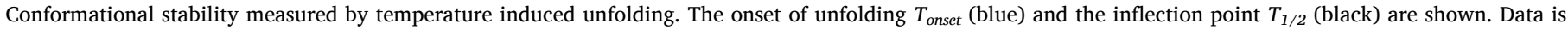

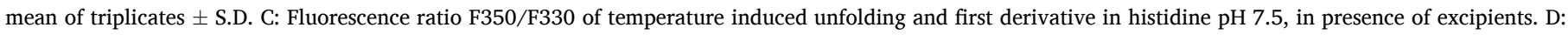

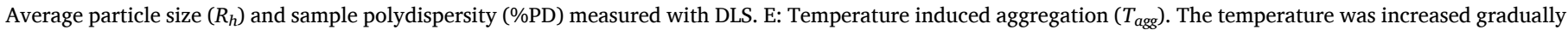

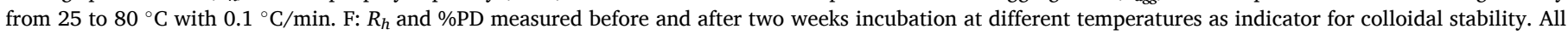

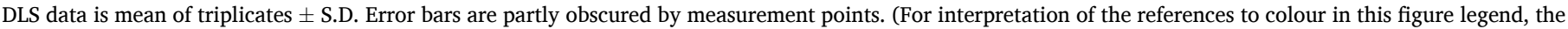
reader is referred to the web version of this article.) 
aggregation propensity and colloidal stability was assessed using DLS. We observed high variation among the measurements, which made manual data analysis necessary. The hydrodynamic radius $\left(R_{h}\right)$ derived from the cumulant fit was in a similar range for all tested conditions and proved to be slightly higher than the theoretical value of $2.5 \mathrm{~nm}$ of the monomer [31] (PDBID: 5AP9 [32]), indicating the presence of a small percentage of aggregates or oligomers in all samples. This was confirmed when analyzed with the regularization fit, which showed a small percentage of oligomeric species in all conditions. The presence of salt seemed to have little or no effect on $R_{h}$ or \%PD (Fig. 1D, Fig. S9). In presence of arginine $\bullet \mathrm{HCl}$ and other tested excipients, the \%PD increased in all conditions (Fig. 1D, Fig. S8). The temperature of aggregation $T_{a g g}$ indicated higher stability with increasing $\mathrm{pH}$ (Fig. 1E, Fig. S9). The presence of salt or excipients appeared to have either no effect or lower $T_{\text {agg }}$ in most conditions, except in histidine buffer $\mathrm{pH}$ 5.5. The diffusion interaction parameter $k_{D}$ was significantly influenced by the presence of oligomers and we could not observe a distinct trend as function of $\mathrm{pH}$ (Fig. S9). In presence of salt or other excipients $k_{D}$ could not be obtained. We measured the colloidal stability storing TLL for two weeks at different temperatures $\left(25,40\right.$, and $50^{\circ} \mathrm{C}$; Fig. $1 \mathrm{~F}$, Fig. S9). TLL appeared to have higher colloidal stability at increasing $\mathrm{pH}$, but the presence of salt had no clear effect. At $\mathrm{pH} 5$ visible aggregation could be observed in all stored samples after a few days, which is in agreement with the observation of a lower $T_{\text {agg }}$.

\subsection{Implementation of SAXS measurements into screening of TLL}

From our screening with conventional high throughput methods, it was difficult to find a beneficial formulation for TLL in regards of higher stability. Therefore, we applied small-angle X-ray scattering (SAXS) to investigate the solution behavior of TLL further. For the purpose of this screening approach, we focused on differences in the SAXS curve shape, especially the part at low $q$ values, the so-called structure factor, which indicated for protein-protein interactions in the sample. We performed the initial data analysis using the derived radius of gyration $\left(R_{g}\right)$, apparent molecular weight, and the shape of the distance distribution function and the dimensionless Kratky plot. By excluding any kind of modelling, this approach should ensure wide and easy applicability. Except in phosphate buffer, we observed repulsion in all samples indicated by a decrease in scattering intensity at low $q$ values (blue arrow) caused by interparticle diffraction effects (Fig. 2). At pH 5.5 however, we observed an associated increase in scattering intensity at medium $q$ values, becoming more pronounced at higher protein concentrations (red arrow), indicating more complex protein-protein interactions (Fig. 2A,B). In histidine $\mathrm{pH}$ 7.5, TLL showed strong repulsion, affecting the scattering intensity at low $q$ (Fig. 2C). In phosphate buffer, we observed significantly reduced repulsion and little oligomerization (Fig. 2D). Protein-protein interactions in a sample that influence the shape of the SAXS curve at low $q$ mean that derived $R_{g}$, MW and $p(r)$ function must be treated with caution and only measurements at low protein concentrations, which show less protein-protein interactions, might be used for data interpretation. For all conditions the derived $R_{g}$ and MW was in the same range (Table S2) and the shape of the distance distribution $(p(r))$ function indicated the presence of small fractions of different oligomeric species (Fig. S10), which is in agreement with our DLS measurements. We did not observe changes at high $q$ values of the
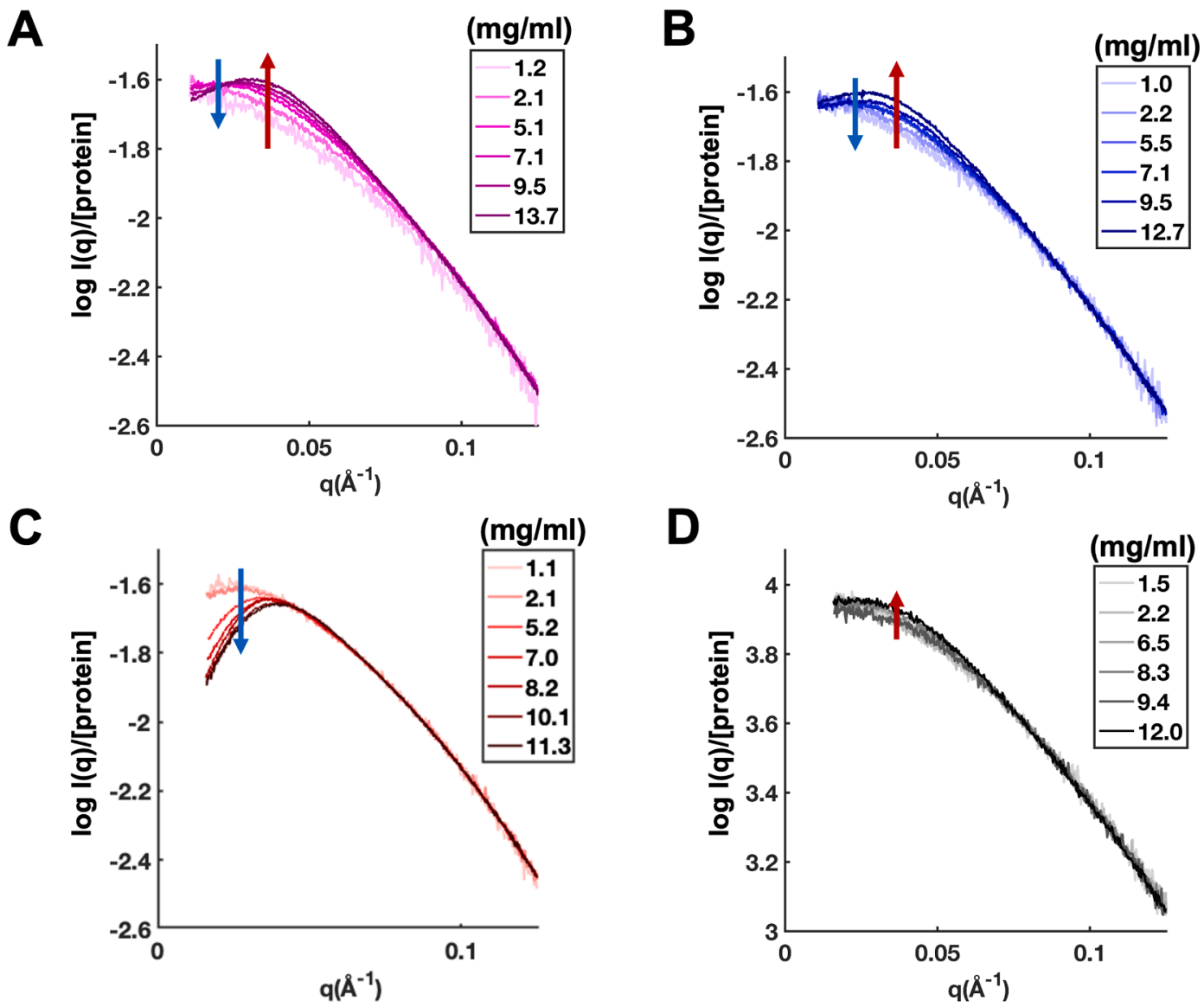

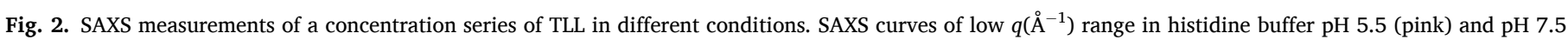

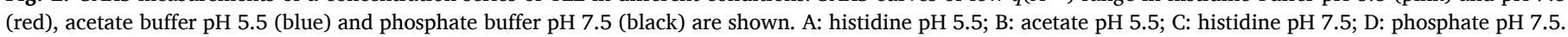

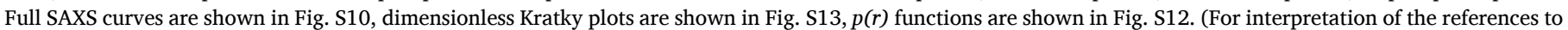
colour in this figure legend, the reader is referred to the web version of this article.) 
SAXS curves between the different conditions or with increasing protein concentration (Fig. S11) meaning that the overall protein shape did not change. We used CRYSOL [33] to compare the experimental scattering curves with theoretical scattering curves of different oligomeric species. We observed the highest similarity of the experimental data to the monomer, but the experimental curve clearly does not represent purely monomeric, non-interacting proteins (Table S4, Fig. S12). The dimensionless Kratky plots indicated for a compact, globular protein (Fig. S13). We observed a small shift of the peak maximum while maintaining the same curve shape at increasing protein concentration, which is most likely caused by changes in protein-protein interaction. To prove that the differences in the SAXS curves at low $q$ among the measured conditions are caused by differences in electrostatic interactions and not by increased oligomerization, we measured SECMALS. The results confirmed that the main species present in solution in all conditions is monomeric with small oligomeric fractions present (Table S5, Fig. S14). We did not observe increased oligomerization or a shift towards larger oligomeric species with increasing concentration. This confirmed that the differences among the conditions observed in SAXS are due to differences in protein-protein interaction interactio.

To examine the effect of salt on TLL in solution, salt was added in different concentrations $(35,70,140 \mathrm{mM} \mathrm{NaCl})$ in histidine buffer $\mathrm{pH}$ 5.5 and pH 7.5 (Fig. 3). Due to a high polydispersity of the sample, $k_{D}$ measurements by DLS were not feasible. However, applying SAXS enabled us to gain information about the effect of salt on protein-protein interactions. The effect was analyzed at protein concentrations of $1 \mathrm{mg} /$ $\mathrm{ml}$ and $5 \mathrm{mg} / \mathrm{ml}$. In both conditions, the addition of salt lowered repulsion in the sample. The dimensionless Kratky plots showed a shift of the peak maximum, while maintaining the overall globular shape, indicating for changes in protein-protein interactions (Fig. S15). The flexibility or folding of TLL seemed to be not affected. As arginine $\bullet \mathrm{HCl}$ showed pronounced effects on TLL stability in the initial screening and changed the shape of TLL's thermal unfolding curves, we chose to further investigate its effect with SAXS. The SAXS curves showed a reduction of repulsion in all conditions (Fig. 4). In phosphate buffer we observed aggregation upon addition of arginine $\bullet \mathrm{HCl}$, indicated by a steep increase of scattering intensity at low $q$. We observed over subtraction of the buffer in all conditions when arginine $\bullet \mathrm{HCl}$ was present, which is usually a sign of direct interaction of buffer components with the protein. The addition of arginine $\bullet \mathrm{HCl}$ had, however, no significant effect on the overall shape of the SAXS curves. The dimensionless Kratky plot showed a significant shift of the peak maximum indicating a change in protein-protein interactions (Fig. S16). Due to the over subtraction, it was difficult to evaluate the flexibility and unfolding in presence of arginine $\bullet \mathrm{HCl}$.

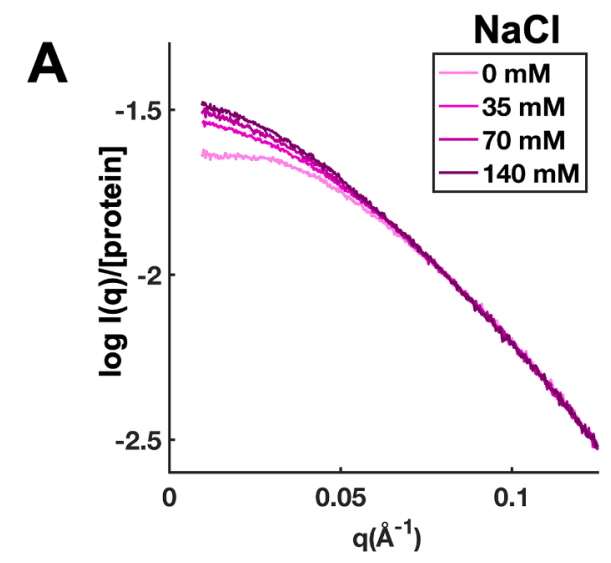

\subsection{Stability screening of RML}

To further determine the utility of SAXS in protein stability screening, the strategy was applied to RML. Despite the structural similarity, the two lipases showed significantly different solution behavior. RML showed a high polydispersity and was indicated as multimodal in almost all conditions $(\% \mathrm{PD}=57 \%)$ when measured with DLS (Fig. 5, Fig. S19). The derived $R_{h}$, therefore showed high standard deviations. The autocorrelation curves showed the presence of a second species in all measured conditions indicated by a second decay in the autocorrelation function (Fig. 5). This led to a poor fit of the cumulant analysis (Fig. S17). The analysis of different fractions present in solution (regularization fit) gave a much better fit of the data and confirmed the presence of larger species (fraction 2) in solution (Table 1). However, the proportion of this second fraction was very low $(>0.1 \%)$ in all conditions. $R_{h}$ of fraction 1 was close to the theoretical $R_{h}$ of TLL, characterizing this fraction as monomeric. The onset of aggregation $T_{\text {agg }}$ showed higher stability upon increasing $\mathrm{pH}$. The conformational stability of RML appeared to be generally lower compared to TLL. Opposite to what we observed for TLL, RML showed two transitions of thermal induced unfolding, while the chemical induced unfolding showed only one transition. RML seemed to have higher conformational stability at high $\mathrm{pH}\left(T_{\text {onset }}, T_{1 / 2}(1), c_{1 / 2}\right.$ ) (Fig. 5, Fig. S18), which is in agreement with the measurement of $T_{\text {agg. }}$. In contrast, the free energy of chemical induced unfolding $\Delta G$ showed lower conformational stability at high $\mathrm{pH}$. The second unfolding transition of thermal induced unfolding $\left(T_{1 / 2}\right.$ (2)) showed no distinct trend. In the first transition the intrinsic fluorescence was less affected, possibly representing the dissociation of the oligomeric species seen in DLS.

The high throughput stability screening of RML did not enable us to determine conclusively which formulation is most beneficial for this enzyme. We investigated the solution behavior of RML further in histidine buffer $\mathrm{pH} 5.5$ and $\mathrm{pH} 7.5$, in acetate buffer $\mathrm{pH}$ 5.5, and phosphate buffer pH 7.5 using SAXS. For RML, $R_{g}$ corresponded to the monomer in all condition (Table S3). However, the pair distribution, $p(r)$, function revealed the presence of a small fraction of oligomeric species in all conditions (Fig. S20), which is in agreement with the DLS measurements. We observed increasing repulsion in the sample in histidine buffer pH 7.5 compared to $\mathrm{pH} 5.5$ (Fig. 6). In acetate and phosphate buffer, we additionally observed aggregate formation, indicated by the upturn of the curves at low $q$ values. The overall shape of the SAXS curves was not affected among the different conditions (Fig. S21). The dimensionless Kratky plots showed a globular shape and did not indicate increased flexibility or unfolding (Fig. S22). The fit of the theoretical SAXS curve to the experimental data showed a good fit to monomeric RML (Table S4, Fig. S24) confirming that the proportion of the

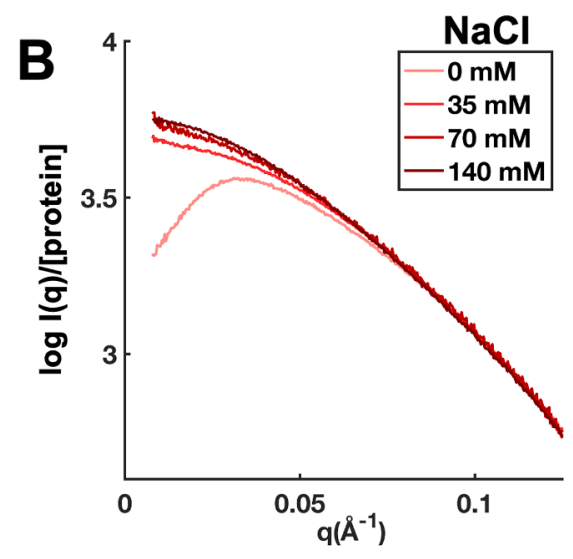

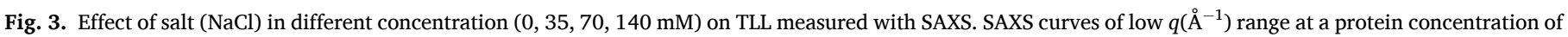

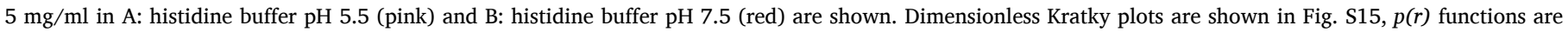
shown in Fig. S14. (For interpretation of the references to colour in this figure legend, the reader is referred to the web version of this article.) 

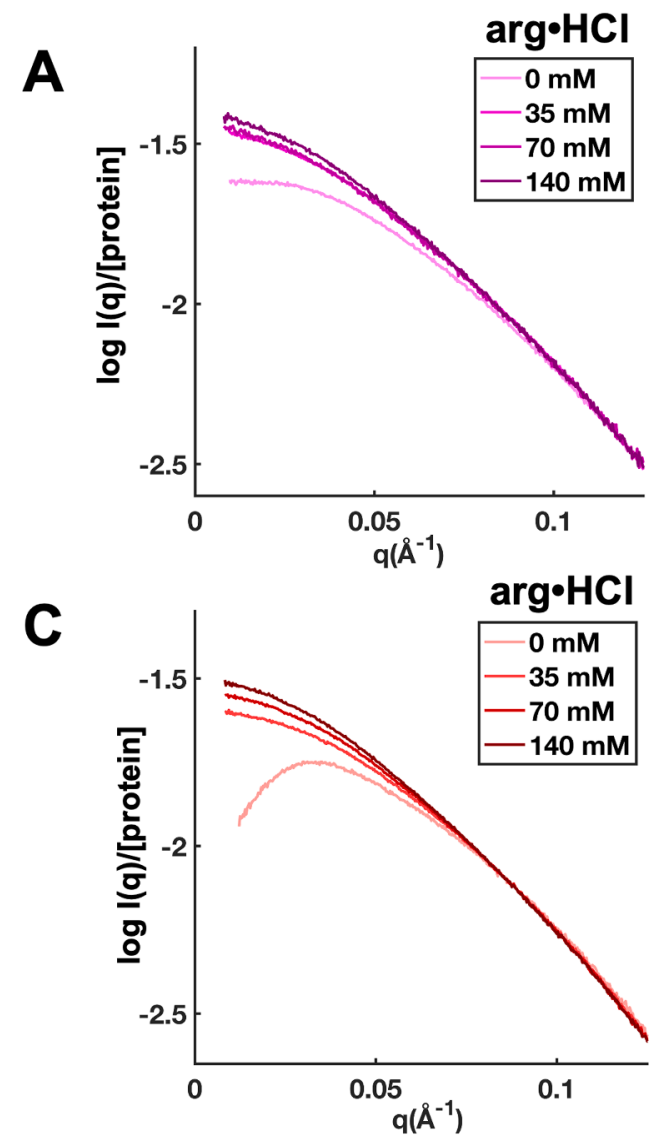

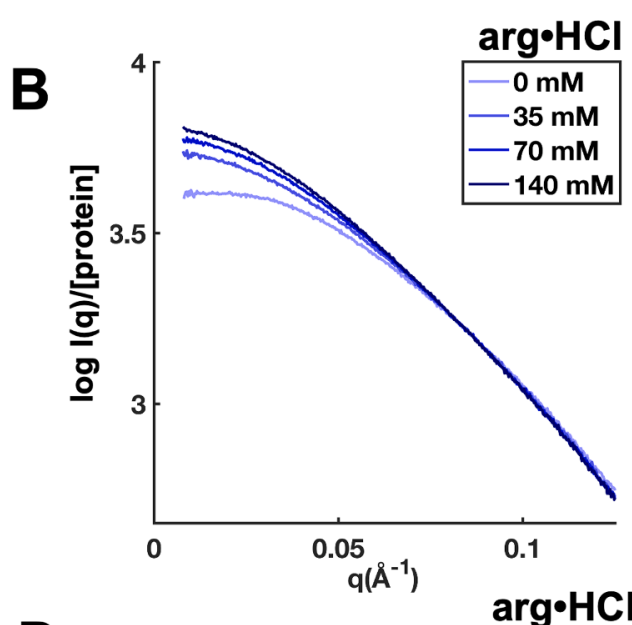

D

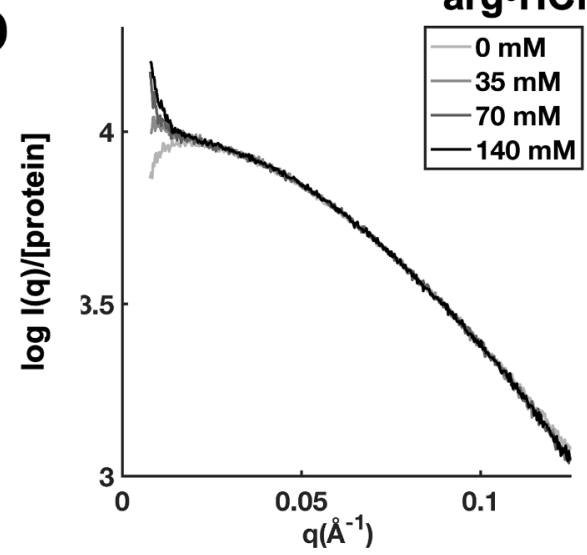

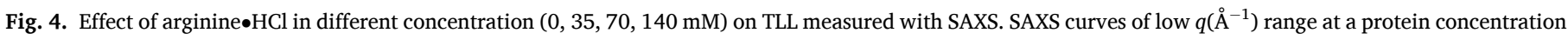

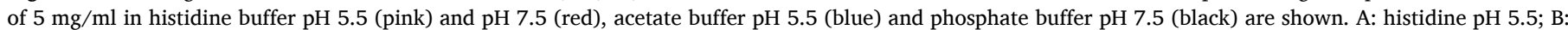

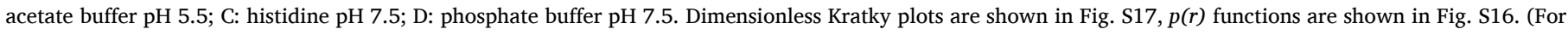
interpretation of the references to colour in this figure legend, the reader is referred to the web version of this article.)

oligomeric species was small and did not have a large effect on the SAXS measurements. To investigate whether the oligomers formed by RML truly differ from oligomers formed by TLL, we measured SEC-MALS. Our measurements confirmed that the main species present in solution is monomeric (Table S6, Fig. S24). The high polydispersity observed in our DLS measurement was caused by the presence of a small fraction of oligomers that were significantly larger than the oligomers observed for TLL.

\section{Discussion}

\subsection{The effect of ionic strength and excipients on protein stability}

TLL and RML are important catalysts in various industrial processes $[15,34]$. They are, however, known to be aggregation prone [23], which complicates the analysis of many high throughput methods. In this case study, we systematically screened the conformational stability and aggregation propensity using an initial screen of $\mathrm{pH}$ and salt and an advanced screen of different buffer systems, including the addition of excipients for selected conditions. In addition to commonly used high throughput methods, SAXS was used as a complementary technique to obtain in-depth knowledge for selected conditions. Despite the high structural identity of TLL and RML, they showed significantly different biophysical behavior in solution. RML showed a two-state unfolding during chemical denaturation, while TLL showed an additional transition resulting in a three-state unfolding. In temperature induced unfolding RML showed two transitions, while TLL showed only one transition. This behavior originated most likely from the dissociation of different oligomeric species present in solution. The measurements of initial dispersion state and colloidal stability using DLS were even more affected by the presence of oligomeric species. Due to the sixth power relationship of scattering intensity to particle radius larger particles such as aggregates introduce significant 'bias' into the measurement, as seen for both lipases investigated in this study. For aggregation prone enzymes or proteins it can therefore prove difficult to assess their stability based on only high throughput methods.

The addition of SAXS to the formulation screening for TLL and RML proved to be very valuable to gain an insight into their solution behavior. Especially the shape of the SAXS curves at low and medium $q$ values revealed significant differences in protein-protein interactions among the tested condition, which can guide formulation studies. The most important long range effect influencing protein-protein interaction are electrostatic forces. Both lipases showed significant more repulsion in the sample in histidine $\mathrm{pH} 7.5$ than $\mathrm{pH}$ 5.5. Repulsion prevents aggregation and is usually beneficial for protein formulation. The reduced repulsion at lower $\mathrm{pH}$ resulted most likely from lower charges close to the protein's isoelectric point (pI) (TLL: 4.4; RML: 4.7). For both lipases the SAXS measurements in phosphate buffer showed reduced repulsion compared to histidine buffer, which can be related to the ionic strength of the buffer (Table S7). The ionic strength of the buffer seemed to screen the charges. TLL seemed to be much more affected by the ionic strength. Likewise, SAXS could show that the addition of $\mathrm{NaCl}$ caused a decrease in repulsion for TLL by screening charges. Our SAXS measurements in combination with SEC-MALS measurements revealed that both lipases are mainly monomeric in solution and no change in the protein structure could be observed. We found that the oligomers formed by the two 
A
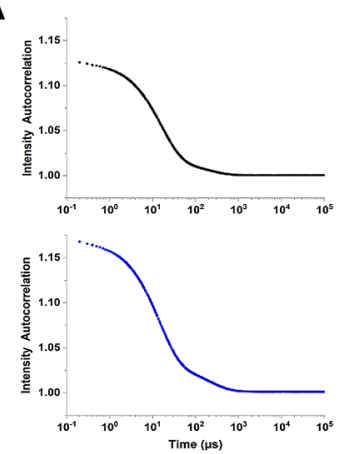

D

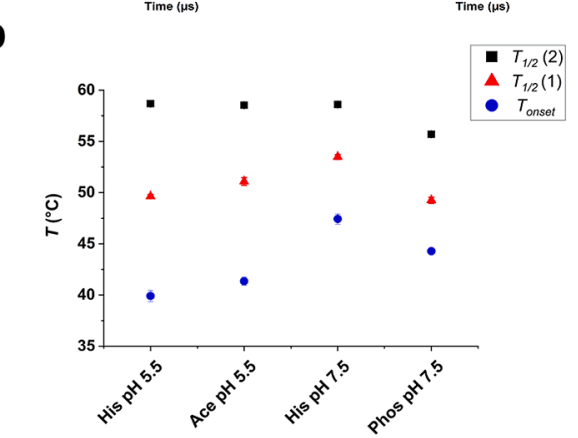

B

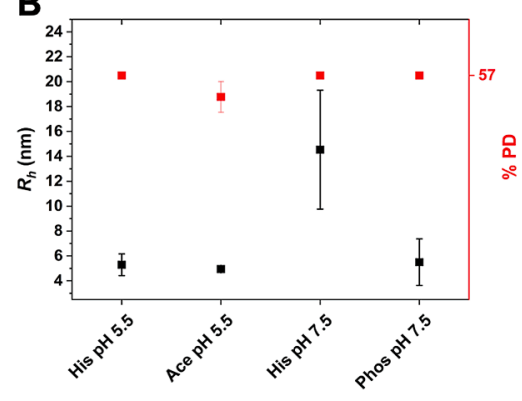

E

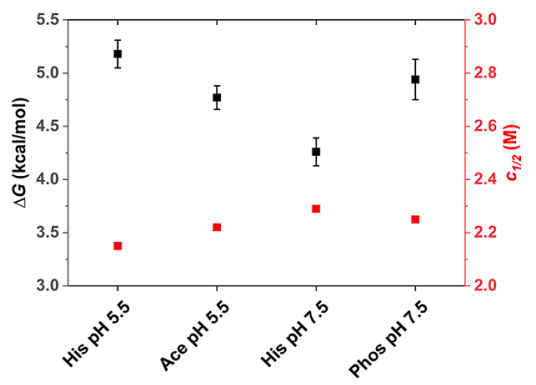

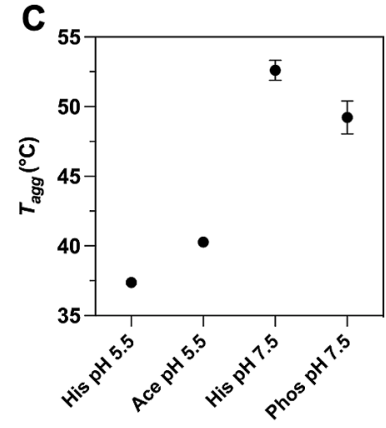

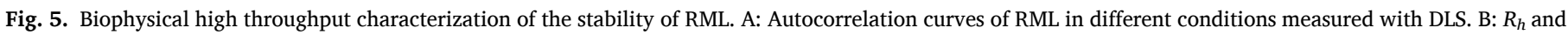

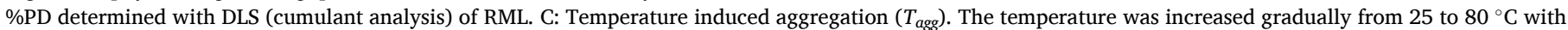

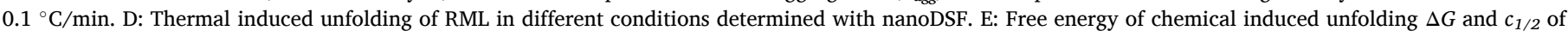
RML in different conditions determined with ICD.

Table 1

Regularization analysis of RML initial dispersion state measured with DLS. Size and proportions of distinct fractions present in solution are shown.

\begin{tabular}{|c|c|c|c|c|c|c|}
\hline \multirow[t]{2}{*}{ Condition } & \multicolumn{3}{|c|}{ Fraction $1(0.1-10 \mathrm{~nm})$} & \multicolumn{3}{|c|}{ Fraction $1(10-100 \mathrm{~nm})$} \\
\hline & $R_{h}(\mathrm{~nm})$ & \%Intensity & \%Mass & $R_{h}(\mathrm{~nm})$ & \%Intensity & \%Mass \\
\hline \multirow[t]{2}{*}{ His pH 5.5} & 2.49 & 57.15 & 99.94 & 33.86 & 39.78 & 0.04 \\
\hline & $(+/-) 0.05$ & $(+/-) 2.97$ & $(+/-) 0.02$ & $(+/-) 2.10$ & $(+/-) 3.14$ & $(+/-) 0.02$ \\
\hline \multirow[t]{2}{*}{ Ace $\mathrm{pH} 5.5$} & 2.7 & 65.75 & 99.93 & 54.94 & 32.12 & 0.05 \\
\hline & $(+/-) 0.03$ & $(+/-) 0.44$ & $(+/-) 0.02$ & $(+/-) 4.31$ & $(+/-) 0.64$ & $(+/-) 0.00$ \\
\hline \multirow[t]{2}{*}{ His $\mathrm{pH} 7.5$} & 2.04 & 29.71 & 99.93 & 42.11 & 70.29 & 0.04 \\
\hline & $(+/-) 0.06$ & $(+/-) 7.76$ & $(+/-) 0.03$ & $(+/-) 1.31$ & $(+/-) 7.76$ & $(+/-) 0.03$ \\
\hline \multirow[t]{2}{*}{ Phos pH 7.5} & 2.87 & 59.68 & 99.97 & 48.1 & 35.83 & 0.03 \\
\hline & $(+/-) 0.04$ & $(+/-) 11.01$ & $(+/-) 0.05$ & $(+/-) 14.09$ & $(+/-) 14.79$ & $(+/-) 0.05$ \\
\hline
\end{tabular}

lipases differed. While TLL formed small oligomers, RML formed large aggregates. This was not obvious from the DLS measurements, which were more affected by the presence of a small fraction of oligomers. SAXS therefore proved to be very valuable to analyze the solution behavior of samples, that have oligomers present. The analysis of the conformational stability was also affected by the presence of oligomeric species introducing changes in the intrinsic fluorescence upon dissociation.

Interestingly, the unfolding curves of thermally induced unfolding measured with nanoDSF showed a significant change upon addition of arginine $\bullet \mathrm{HCl}$ and $\mathrm{NaCl}$. The SAXS measurements showed a reduction of repulsion in presence of arginine $\bullet \mathrm{HCl}$ and $\mathrm{NaCl}$. In presence of arginine $\bullet \mathrm{HCl}$, the subtraction of the buffer measurement in SAXS led to over subtraction indicating direct interaction of buffer components with the protein, which was not observed in the presence of $\mathrm{NaCl}$. This led us to believe that arginine interacts directly with the protein, while $\mathrm{NaCl}$ only screens protein charges. Betaine has been shown to increase TLL's thermal stability [24], which could also be observed in some conditions for arginine $\bullet \mathrm{HCl}$. However, arginine $\bullet \mathrm{HCl}$ clearly has a negative influence on TLL aggregation propensity.

When comparing the conclusions from our SAXS measurements with the initial high throughput screening, we found that $T_{\text {agg }}$ gave the best prediction of protein-protein interactions in solution and can serve as a good indicator for formulation studies. The trend of the measured aggregation temperature followed the same trend as the repulsion observed in SAXS. Addition of arginine $\bullet \mathrm{HCl}$ or $\mathrm{NaCl}$ led in our study to a reduction of repulsion. However, the protein's conformational stability seemed to be improved by the addition of arginine $\bullet \mathrm{HCl}$ or $\mathrm{NaCl}$. This effect might be explained by screening of exposed charges or even direct interaction as seen in our SAXS measurements for arginine $\bullet \mathrm{HCl}$. In this way, SAXS may be used to explain initial screening data that at first glance give contradicting results.

\subsection{Sample consumption, automation and information content of the applied methods}

Independent replicates of selected conditions between the initial and the advanced screening were performed for all high throughput methods to ensure the robustness of the methods. All replicates were in good agreement. For ICD, there are highly automated systems available, but the sample consumption is approx. 10 times higher than for the other high throughput methods used in this study. nanoDSF appeared to be the most robust method and the low sample consumption and high degree of automation available is advantageous. However, the presence of 
A

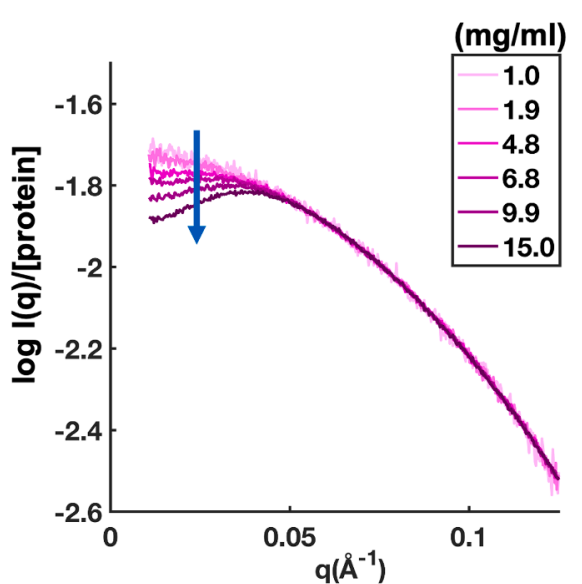

C

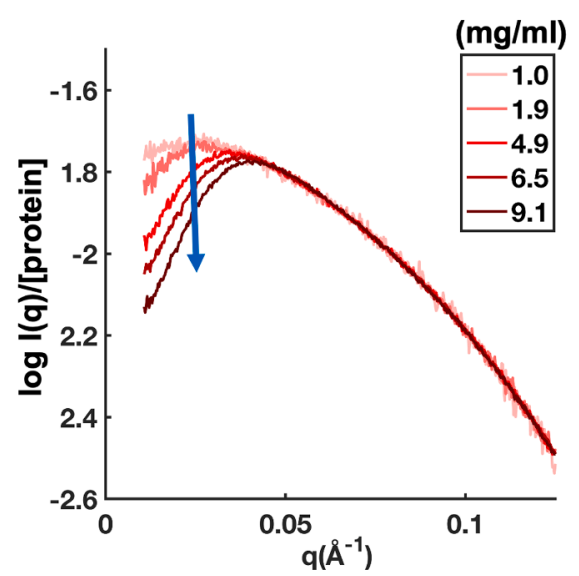

B

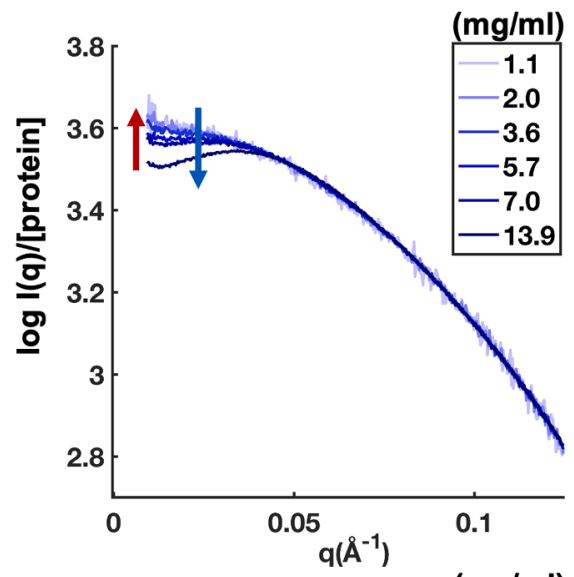

D

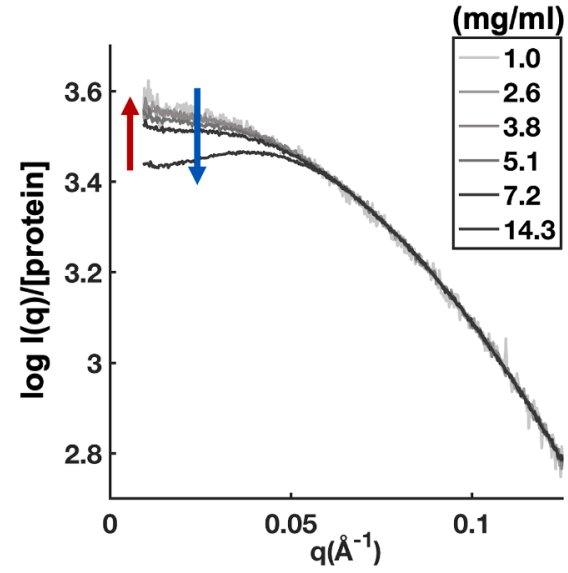

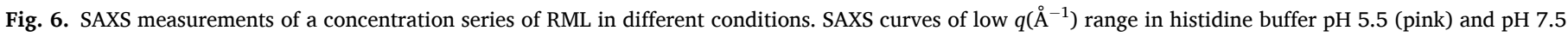

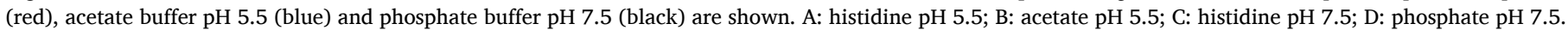

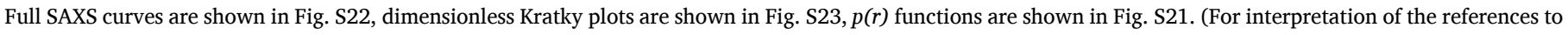
colour in this figure legend, the reader is referred to the web version of this article.)

oligomers or aggregates can influence the measurements as seen in this study. Newer systems integrate DLS allowing simultaneous assessment of thermal stability and heterogeneity of the sample. In our study, the initial dispersion state and colloidal stability was assessed with high throughput plate based DLS. A main advantage of DLS is the low sample consumption. However, DLS is very sensitive towards small amounts of large particles like aggregates in solution, leading to high variability in the measurements and may cause difficulties when analyzing and comparing replicates. In our study, this complicated the assessment of aggregation prone proteins. Sensitive DLS measurements indicating interparticle interactions ( $k_{D}$ measurements) could therefore not be obtained in this study. Instead, we used the scattering intensity at low $q$ values in SAXS measurements, which is very sensitive towards interparticle interaction (repulsion and aggregation) and can pick up variations among the different conditions. These variations might be useful predictors for long-term behavior of a protein. The inclusion of SAXS into the screening, gave valuable insights in the complex solution behavior of the lipases at different $\mathrm{pH}$, different buffer systems and on the addition of salt and arginine $\bullet \mathrm{HCl}$ to the protein. Recent advances in SAXS included automatic sample changing [35,36] automated data reduction [5], processing [4] and fitting [37]. Additionally, several methods, that limit the sample consumption, like plate-based methods [4] or fluidic chips have been developed [38,39]. This development will aid the implementation of SAXS as a high throughput screening tool, which is not yet possible with other structural techniques. At the current state of SAXS, it is possible to measure and analyze protein stability for selected conditions. SAXS is therefore especially useful at a later stage of protein screening to assess different formulation of final candidates.
Further development in terms of throughput and data treatment of nonideal solutions will lead to an improved use of SAXS and wider applicability in industrial screening.

\section{Conclusion}

Our case study of the industrial relevant lipases from Thermomyces lanuginosus (TLL) and Rhizomucor miehei (RML) showed how SAXS gives valuable information on the solution behavior of a protein when included into a systematic formulation screen. Information about interparticle interactions may be derived from the shape of the SAXS curves. The distance distribution $(p(r))$ function indicates directly for heterogeneity in the sample. From the dimensionless Kratky plot information about the flexibility and folding state of the protein can be derived. Simple determination of the apparent molecular weight and radius of gyration can be used as quality parameters of the protein in certain conditions. These can be derived from SAXS data without performing modelling, which requires extensive user intervention. Despite the larger sample consumption and lower degree of automation, SAXS is especially valuable in the later stage of protein development. Therefore, we propose SAXS as a complementary technique in the development of industrially relevant proteins.

\section{Declaration of Competing Interest}

The authors declare that they have no known competing financial interests or personal relationships that could have appeared to influence the work reported in this paper. 


\section{Acknowledgements}

The synchrotron SAXS data was collected at beamline P12 operated by EMBL Hamburg at the Petra II storage ring (DESY, Hamburg, Germany. For local support we thank Melissa Gräwert, Stefano Da Vela, Andrey Gruzinov, Karen Manalastas (all: EMBL, Hamburg).

\section{Data Availability}

All data is publicly available from the PIPPI database https://pippidata.kemi.dtu.dk/

\section{Authors contribution}

CP wrote the manuscript with support from SM, AN and PH. AK performed and analyzed the SEC-MALS experiments. PH, AN, WS and GHJP planned and supervised the study. CP conducted, analyzed and interpreted the experiments on TLL. SM conducted and analyzed the experiments on RML. CP and SM interpreted the experiments on RML. All authors corrected and approved the final manuscript.

\section{Funding}

This work was funded by European Union's Horizon 2020 research and innovation program (grant agreement no. 675074).

We thank the Danish Agency for Science, Technology, and Innovation for funding the instrument center DanScatt.

\section{Appendix A. Supplementary data}

Supplementary data to this article can be found online at https://doi. org/10.1016/j.ejpb.2021.08.018.

\section{References}

[1] A. Jarasch, H. Koll, J.T. Regula, M. Bader, A. Papadimitriou, H. Kettenberger, Developability assessment during the selection of novel therapeutic antibodies, J. Pharm. Sci. 104 (6) (2015) 1885-1898, https://doi.org/10.1002/jps.24430.

[2] P.J. Carter, Potent antibody therapeutics by design, Nat. Rev. Immunol. 6 (5) (2006) 343-357, https://doi.org/10.1038/nri1837.

[3] D.I. Svergun, M.H.J. Koch, P.A. Timmins, R.P. May, Small Angle X-Ray and Neutron Scattering from Solutions of Biological Macromolecules, Oxford University Press, Oxford, 2013.

[4] G.L. Hura, et al., Robust, high-throughput solution structural analysis by small angle X-ray scattering (SAXS), Nat. Methods 6 (8) (2009) 606-612, https://doi. org/10.1038/nmeth.1353.Robust.

[5] D. Franke, A.G. Kikhney, D.I. Svergun, Automated acquisition and analysis of small angle X-ray scattering data, Nucl. Instruments Methods Phys. Res. 689 (2012) $52-59$.

[6] A. Ghanem, H.Y. Aboul-Enein, Application of lipases in kinetic resolution of racemates, Chirality 17 (1) (2005) 1-15, https://doi.org/10.1002/(ISSN)1520636X10.1002/chir.v17:110.1002/chir.20089.

[7] A. Ghanem, Trends in lipase-catalyzed asymmetric access to enantiomerically pure/enriched compounds, Tetrahedron 63 (8) (2007) 1721-1754, https://doi. org/10.1016/j.tet.2006.09.110.

[8] A. Liljeblad, L.T. Kanerva, Biocatalysis as a profound tool in the preparation of highly enantiopure $\beta$-amino acids, Tetrahedron 62 (25) (2006) 5831-5854, https://doi.org/10.1016/j.tet.2006.03.109.

[9] F. Hamam, F. Shahidi, Enzymatic incorporation of capric acid into a single cell oil rich in docosahexaenoic acid and docosapentaenoic acid and oxidative stability of the resultant structured lipid, Food Chem. 91 (4) (2005) 583-591, https://doi.org/ 10.1016/j.foodchem.2004.05.024.

[10] P. Villeneuve, N. Barouh, B. Baréa, G. Piombo, M.C. Figueroa-Espinoza, F. Turon, M. Pina, R. Lago, Chemoenzymatic synthesis of structured triacylglycerols with conjugated linoleic acids (CLA) in central position, Food Chem. 100 (4) (2007) 1443-1452, https://doi.org/10.1016/j.foodchem.2005.12.018.

[11] T. Porsgaard, X. Xu, J. Göttsche, H. Mu, Differences in the intramolecular structure of structured oils do not affect pancreatic lipase activity in vitro or the absorption by rats of (n-3) fatty acids, J. Nutr. 135 (7) (2005) 1705-1711, https://doi.org/ 10.1093/jn/135.7.1705.

[12] P.T. Vasudevan, M. Briggs, Biodiesel production - Current state of the art and challenges, J. Ind. Microbiol. Biotechnol. 35 (5) (2008) 421-430, https://doi.org/ 10.1007/s10295-008-0312-2
[13] F. Faigl, A. Thurner, F. Farkas, M. Battancs, L. Poppe, Synthesis and enantioselective rearrangement of (Z)-4-triphenylmethoxy-2,3-epoxybutan-1-ol enantiomers, Chirality 19 (2006) 197-202, https://doi.org/10.1002/chir.

[14] Z.Y. Wang, N. Li, M.H. Zong, A simple procedure for the synthesis of potential 6azauridine prodrugs by Thermomyces lanuginosus lipase, J. Mol. Catal. B Enzym. 59 (1-3) (2009) 212-219, https://doi.org/10.1016/j.molcatb.2009.03.002.

[15] R.C. Rodrigues, R. Fernandez-lafuente, Journal of Molecular Catalysis B : Enzymatic Lipase from Rhizomucor miehei as an industrial biocatalyst in chemical process, Journal Mol. Catal. B, Enzym. 64 (1-2) (2010) 1-22, https://doi.org/ 10.1016/j.molcatb.2010.02.003.

[16] C.D. Anobom, A.S. Pinheiro, R.A. De-Andrade, E.C.G. Aguieiras, G.C. Andrade, M. V. Moura, R.V. Almeida, D.M. Freire, From structure to catalysis: Recent developments in the biotechnological applications of lipases, Biomed. Res. Int 2014 (2014) 1-11, https://doi.org/10.1155/2014/684506.

[17] U. Derewenda, et al., Conformational lability of lipases observed in the absence of an oil- water interface: Crystallographic studies of enzymes from the fungi Humicola lanuginosa and Rhizopus delemar, J. Lipid Res. 35 (3) (1994) 524-534, https://doi.org/10.2210/pdb1tib/pdb.

[18] Z.S. Derewenda, U. Derewenda, G.G. Dodson, The crystal and molecular structure of the Rhizomucor miehei triacylglyceride lipase at 1.9 A resolution, J. Mol. Biol. 227 (3) (1992) 818-839, https://doi.org/10.1016/0022-2836(92)90225-9.

[19] F. Madeira, et al., The EMBL-EBI search and sequence analysis tools APIs in 2019, Nucleic Acids Res., 47(W1), pp. W636-W641, 2019, doi: 10.1093/nar/gkz268.

[20] Schrödinger, LLC, "The \{PyMOL\} Molecular Graphics System, Version 1.8," Nov. 2015.

[21] M.L.M. Fernandes, N. Krieger, A.M. Baron, P.P. Zamora, L.P. Ramos, D.A. Mitchell, Hydrolysis and synthesis reactions catalysed by Thermomyces lanuginosa lipase in the AOT/Isooctane reversed micellar system, J. Mol. Catal. B Enzym. 30 (1) (2004) 43-49, https://doi.org/10.1016/j.molcatb.2004.03.004.

[22] R.C. Rodrigues, C.A. Godoy, G. Volpato, M.A.Z. Ayub, R. Fernandez-Lafuente, J. M. Guisan, Immobilization-stabilization of the lipase from Thermomyces lanuginosus: Critical role of chemical amination, Process Biochem. 44 (9) (2009) 963-968, https://doi.org/10.1016/j.procbio.2009.04.015.

[23] J.M. Palomo, M. Fuentes, G. Fernández-Lorente, C. Mateo, J.M. Guisan, R. Fernández-Lafuente, General trend of lipase to self-assemble giving bimolecular aggregates greatly modifies the enzyme functionality, Biomacromolecules 4 (1) (2003) 1-6, https://doi.org/10.1021/bm025729+.

[24] T. Söderlund, K. Zhu, A. Jutila, P.K.J. Kinnunen, Effects of betaine on the structural dynamics of Thermomyces (Humicola) lanuginosa lipase, Colloids Surf. B Biointerfaces 26 (1-2) (2002) 75-83, https://doi.org/10.1016/S0927-7765(02) 00032-2.

[25] S. Al-Zuhair, Production of biodiesel: Possibilities and challenges, Biofuels, Bioproducts and Biorefining. 1 (1) (2007) 57-66, https://doi.org/10.1002/(ISSN) 1932-103110.1002/bbb.v1:110.1002/bbb.2.

[26] M. Noel, D. Combes, Effects of temperature and pressure on Rhizomucor miehei lipase stability, J. Biotechnol. 102 (1) (2003) 23-32, https://doi.org/10.1016/ S0168-1656(02)00359-0.

[27] L. Gentiluomo, et al., Advancing Therapeutic Protein Discovery and Development through Comprehensive Computational and Biophysical Characterization, 2020, doi: 10.1021/acs.molpharmaceut.9b00852.

[28] C. Pohl, M. Zalar, I.E. Bialy, S. Indrakumar, G.H.J. Peters, W. Friess, A P. Golovanov, W.W. Streicher, A. Noergaard, P. Harris, The effect of point mutations on the biophysical properties of an anti-microbial peptide: development of a screening protocol for peptide stability screening, Mol. Pharm. 17 (9) (2020) 3298-3313, https://doi.org/10.1021/acs.molpharmaceut.0c0040610.1021/acs. molpharmaceut.0c00406.s001.

[29] D. Franke, et al., ATSAS 2.8: a comprehensive data analysis suite for small-angle scattering from macromolecular solutions, J. Appl. Crystallogr. 50 (4) (2017) 1212-1225, https://doi.org/10.1107/s1600576717007786.

[30] P.V. Konarev, V.V. Volkov, A.V. Sokolova, M.H.J. Koch, D.I. Svergun, PRIMUS: A Windows PC-based system for small-angle scattering data analysis, J. Appl. Crystallogr. 36 (5) (2003) 1277-1282, https://doi.org/10.1107/ S0021889803012779.

[31] P.J. Fleming, K.G. Fleming, HullRad: Fast calculations of folded and disordered protein and nucleic acid hydrodynamic properties, Biophys. J. 114 (4) (2018) 856-869, https://doi.org/10.1016/j.bpj.2018.01.002.

[32] J. Skjold-Jørgensen, J. Vind, O.V. Moroz, E. Blagova, V.K. Bhatia, A. Svendsen, K. S. Wilson, M.J. Bjerrum, Controlled lid-opening in Thermomyces lanuginosus lipase- An engineered switch for studying lipase function, Biochim. Biophys. Acta Proteins Proteomics 1865 (1) (2017) 20-27, https://doi.org/10.1016/j. bbapap.2016.09.016.

[33] D. Svergun, C. Barberato, M.H. Koch, CRYSOL - A program to evaluate X-ray solution scattering of biological macromolecules from atomic coordinates, J. Appl. Crystallogr. 28 (6) (1995) 768-773, https://doi.org/10.1107/ S0021889895007047.

[34] R. Fernandez-Lafuente, Lipase from Thermomyces lanuginosus: Uses and prospects as an industrial biocatalyst, J. Mol. Catal. B Enzym. 62 (3-4) (2010) 197-212, https://doi.org/10.1016/j.molcatb.2009.11.010.

[35] C.E. Blanchet, A.V. Zozulya, A.G. Kikhney, D. Franke, P.V. Konarev, W. Shang, R. Klaering, B. Robrahn, C. Hermes, F. Cipriani, D.I. Svergun, M. Roessle, Instrumental setup for high-throughput small-and wide-angle solution scattering at the X33 beamline of EMBL Hamburg, J. Appl. Crystallogr. 45 (3) (2012) 489-495, https://doi.org/10.1107/S0021889812013490.

[36] S.S. Nielsen, M. Møller, R.E. Gillilan, High-throughput biological small-angle X-ray scattering with a robotically loaded capillary cell, J. Appl. Crystallogr. 45 (2) (2012) 213-223, https://doi.org/10.1107/S0021889812000957. 
[37] M.V. Petoukhov, P.V. Konarev, G. Kikhney, I. Dmitri, ATSAS 2.1 - Supported smallangle scattering data analysis, Appl. Crystallogr. 40 (2007) s223-s228.

[38] K.N. Toft, B. Vestergaard, S.S. Nielsen, D. Snakenborg, M.G. Jeppesen, J.

K. Jacobsen, L. Arleth, J.P. Kutter, High-throughput small angle X-ray scattering from proteins in solution using a microfluidic front-end, Anal. Chem. 80 (10) (2008) 3648-3654, https://doi.org/10.1021/ac800011y.
[39] J.P. Lafleur, D. Snakenborg, S.S. Nielsen, M. Møller, K.N. Toft, A. Menzel, J. K. Jacobsen, B. Vestergaard, L. Arleth, J.P. Kutter, Automated microfluidic samplepreparation platform for high-throughput structural investigation of proteins by small-angle X-ray scattering, J. Appl. Crystallogr. 44 (5) (2011) 1090-1099, https://doi.org/10.1107/S002188981103006810.1107/S0021889811030068/ ea5144sup1.pdf. 